\title{
Strategies for Interfering With Bacterial Early Stage Biofilms
}

\author{
Jingyuan Fut, Yuning Zhang', Shiyu Lin', Wei Zhang, Gang Shu, Juchun Lin, Haohuan Li, \\ Funeng Xu, Huaqiao Tang, Guangneng Peng, Ling Zhao, Shiqi Chen and Hualin Fu*
}

Innovative Engineering Research Center of Veterinary Pharmaceutics, Department of Pharmacy, College of Veterinary

Medicine, Sichuan Agricultural University, Chengdu, China

Biofilm-related bacteria show high resistance to antimicrobial treatments, posing a remarkable challenge to human health. Given bacterial dormancy and high expression of efflux pumps, persistent infections caused by mature biofilms are not easy to treat, thereby driving researchers toward the discovery of many anti-biofilm molecules that can intervene in early stage biofilms formation to inhibit further development and maturity. Compared with mature biofilms, early stage biofilms have fragile structures, vigorous metabolisms, and early attached bacteria are higher susceptibility to antimicrobials.

OPEN ACCESS

Edited by:

Giovanna Batoni,

University of Pisa, Italy

Reviewed by:

Mariana Carmen Chifiriuc,

University of Bucharest, Romania Katharina Richter,

The University of Adelaide, Australia

*Correspondence:

Hualin Fu

fuhl2005@sohu.com

${ }^{\dagger}$ These authors have contributed equally to this work

Specialty section: This article was submitted to Antimicrobials, Resistance and Chemotherapy,

a section of the journal

Frontiers in Microbiology

Received: 04 March 2021

Accepted: 03 May 2021

Published: 08 June 2021

Citation:

Fu J, Zhang Y, Lin S, Zhang W,

Shu G, Lin J, Li H, Xu F, Tang H, Peng $G$, Zhao L, Chen $S$ and Fu $H$ (2021) Strategies for Interfering With

Bacterial Early Stage Biofilms.

Front. Microbiol. 12:675843. doi: 10.3389/fmicb.2021.675843
Thus, removing biofilms at the early stage has evident advantages. Many reviews on anti-biofilm compounds that prevent biofilms formation have already been done, but most of them are based on compound classifications to introduce anti-biofilm effects. This review discusses the inhibitory effects of anti-biofilm compounds on early stage biofilms formation from the perspective of the mechanisms of action, including hindering reversible adhesion, reducing extracellular polymeric substances production, interfering in the quorum sensing, and modifying cyclic di-GMP. This information can be exploited further to help researchers in designing new molecules with anti-biofilm activity.

Keywords: bacteria, early stage biofilms, anti-biofilm molecules, mechanisms, quorum sensing, c-di-GMP

\section{INTRODUCTION AND BIOFILMS FORMATION}

At present, most chronic and recurrent infections are associated with biofilms, such as cystic fibrosis and urinary tract infections in humans (Lories et al., 2020; Rumbaugh and Sauer, 2020). Biofilms are defined as three-dimensional (3D) structures that microbial cells attach to a surface, or to each other and embed in self-secreted extracellular polymeric substances (EPSs). EPSs consist of exopolysaccharides, extracellular DNA (eDNA), proteins, and other minor components (Yan and Bassler, 2019; Zea et al., 2020). Once bacteria form biofilms, EPSs will act as a physical and chemical barrier to protect internal bacteria. On the one hand, EPSs enable bacteria to escape the immune system by covering bacterial surface epitopes, releasing extracellular nucleases to degrade neutrophil extracellular traps, and inducing the M2 activation of macrophages (Paharik and Horswill, 2016; Parastan et al., 2020). On the other hand, EPSs remarkable enhance bacterial resistance to antimicrobials (Karygianni et al., 2020). And the resident cells will be spread into new sites to start a new life cycle of biofilms (Girish et al., 2019). These all contribute to the refractory and persistence of biofilm infections.

Biofilms formation is described as early, middle, and late stages (Mohammed et al., 2018; Zou and Liu, 2020). Early stage biofilms consist of reversible and irreversible adhesion stages (Karygianni et al., 2020; Parastan et al., 2020). In the reversible adhesion stage, planktonic bacteria 
approach and attach to the surface by means of surface appendages such as flagella and pili. However, the mobility of bacteria can easily overcome the bacteria-surface interaction and return to the planktonic state. In the irreversible adhesion stage, initially attached bacteria secrete EPS to bind to the surface covalently, gradually completing the firm attachment. In the early stage, attached bacteria can also aggregate through type IV pili-mediated twitching motilities and use EPSs to adhere surface-associated cells (Rabin et al., 2015; Wang et al., 2020). Middle stage biofilms include the formation of microcolonies and colonies. With the accumulation of bacteria, secreted EPSs increase, gradually forming a layer of water film on the surface of bacteria, and microcolonies are formed. Microcolonies further develop into colonies. The late stage is the maturation and detachment of biofilms. Mature biofilms appear as a 3D network structure with compact structure and coordinated functions. After maturity, biofilms rupture, and bacteria are dispersed to planktonic forms to start a new life cycle of biofilms.

\section{REGULATION SYSTEMS IN BIOFILMS FORMATION}

Given that biofilms are the main state of bacteria, the quorum sensing (QS) system and cyclic di-GMP (c-di-GMP) signaling pathway have been shown to play a pivotal role in biofilms formation for various bacterial species, such as Pseudomonas aeruginosa ( $P$. aeruginosa), Escherichia coli (E. coli), Staphylococcus aureus (S. aureus) (Solano et al., 2014; Jenal et al., 2017).

QS is a cell-to-cell communication in which bacteria secrete and detect signal molecules. Once a threshold level is reached, specific signals are activated to coordinate pathogenic behaviors, such as biofilms formation, bioluminescence and antibiotic resistance (Stephens and Bentley, 2020). The connection between QS and biofilms formation has been widely described. In the process of biofilms formation, the QS system regulates bacterial movement, EPSs production, and virulence factor secretion (Xia et al., 2012; Lee et al., 2018), whereas motility and EPSs play an important role in the initial adhesion stage.

Another important regulation system is c-di-GMP signaling pathway. The c-di-GMP is an important second messenger molecule that exists widely in bacteria, since its initial discovery as an allosteric factor regulating cellulose biosynthesis in Gluconacetobacter xylinus, bacterial movement and biofilms formation regulated by the c-di-GMP have grown (Rabin et al., 2015). Diguanylate cyclases (DGCs) containing the GGDEF domain and phosphodiesterases (PDEs) containing the EAL or HD-GYP domain are, respectively, responsible for the synthesis and degradation of c-di-GMP. Generally, a high c-di-GMP content is favorable for biofilms formation. In the reversible adhesion stage, c-di-GMP inhibits the activity of ATPase. Thus, FleQ cannot regulate downstream flagellar genes, thereby preventing the synthesis of flagella. This inhibitory effect can eliminate surface dynamics to make bacteria stick to the surface stably, and promote irreversible transformation. In the irreversible adhesion stage, c-di-GMP promotes EPS production. For example, in $P$. aeruginosa, the combination of c-di-GMP with FleQ relieves the inhibitory effect of FleQ on the pel promoter and activates transcription to produce pel polysaccharides (Baraquet et al., 2012). In E. coli, c-di-GMP binds to the PgaCD complex, which has polysaccharide synthesis and transport activity, thereby activating glycosyltransferase activity and promoting the $N$-acetyl glucosamine (GlcNAc) production (Steiner et al., 2013). This facilitation can enhance bacterial adhesion and further contribute to early stage biofilms formation.

\section{RATIONALES FOR TARGETING THE EARLY STAGE BIOFILMS}

During biofilms formation, bacteria exhibit a dynamic change in drug sensitivity. In the early stage of biofilm formation ( $\mathrm{Gu}$ et al., 2019), bacteria switch from the free-swimming phase to the surface-attached phase. The cell-surface interaction triggers some mechanically sensitive channels on cell wall opening, making the bacteria susceptible to antimicrobials. At the same time, attached cells get close to each other to initiate active cell-cell interaction. During this process, cells divide, grow, and become increasingly sensitive to antimicrobials. However, in the middle and late stages, high expression of efflux pumps, horizontal gene transfer, and EPS matrix protection can significantly reduce the antimicrobial susceptibility (Venkatesan et al., 2015; Hall and Mah, 2017). Surface-attached cells can be more sensitive to antibiotics than planktonic cells during early stage, and the 3D structures of early stage biofilms have not been formed and are characterized by fragile structures. Removing biofilms at this time has evident advantages compared with removing at the mature stage. Inhibiting the formation of early stage biofilms can prevent their development into mature biofilms, thereby reducing biofilm-related infections.

Reversible adhesion, EPSs production, QS system, and c-diGMP levels are important factors affecting early stage biofilms development. Therefore, reducing motility and EPSs production, and inhibiting QS system and c-di-GMP pathways are effective methods to inhibit early stage biofilms formation. Biofilms prevention strategies have been studied, however, many of these strategies are based on compounds classifications to discuss the anti-biofilm effects, such as antibiotics, phytochemicals, and antimicrobial peptides. Here, we make an effort to review the inhibitory effects of anti-biofilm molecules on early stage biofilms formation from the perspective of the mechanisms of action, providing help to researchers in designing new molecules with anti-biofilm activity. At the same time, we state the disadvantages of each solution in Table $\mathbf{1}$.

\section{REDUCING REVERSIBLE ADHESION}

As shown in the introduction of biofilms formation, reversible adhesion is the first step of early stage biofilms formation. In the reversible adhesion stage, bacteria have not yet secreted EPSs, and are only weakly bound to the surface. The instability of the bacteria makes it easy to be removed and return to planktonic 
TABLE 1 | The disadvantages of anti-early stage biofilms strategies.

\begin{tabular}{|c|c|c|}
\hline \multicolumn{2}{|c|}{ Anti-early stage biofilms strategies } & \multirow{2}{*}{$\begin{array}{l}\text { Disadvantages } \\
\text { Only applies to device-related infections }\end{array}$} \\
\hline Reducing reversible adhesion & Designing antibacterial surfaces & \\
\hline & Reducing motility & $\begin{array}{l}\text { Cannot completely inhibit biofilms formation when used } \\
\text { alone }\end{array}$ \\
\hline \multirow[t]{2}{*}{ Inhibiting EPS production } & Reducing exopolysaccharides production & Antibiotics can easily lead to multidrug-resistant microbes \\
\hline & $\begin{array}{l}\text { Reducing extracellular protein production } \\
\text { Reducing eDNA production }\end{array}$ & $\begin{array}{l}\text { Plant-derived components are less effective in in vivo } \\
\text { models; how far plant-based treatments can be applied in } \\
\text { the near future is not clear }\end{array}$ \\
\hline Inhibition of the QS system & & Current QS inhibitors are only suitable for a few bacteria \\
\hline Targeting c-di-GMP signaling & & The rate of discovery of inhibitors has lagged behind \\
\hline
\end{tabular}

state, hindering the development of biofilms. Reversible adhesion is affected by surface properties and bacterial surface appendages such as flagella and pili. Therefore, this section focuses on the strategy of designing antibacterial surfaces and inhibiting the biological activity of flagella and pili.

\section{Designing Antibacterial Surfaces}

Applying hydrophilic coatings on the surface is a common method to reduce bacterial adhesion in the initial stage (Figure 1). Based on the repulsive effect between different charges, the surface of bacteria has hydrophobic properties, and applying hydrophilic coatings on the surface can reduce bacterial adhesion and prevent early stage biofilms formation. Commonly used hydrophilic coatings include hyaluronic acid, polyethylene glycol (PEG), and 2-methacryloyloxy ethyl phosphorylcholine (MPC). MPC contains a phospholipid polar group similar to the cell membrane structure, which can effectively reduce protein adsorption and bacterial adhesion, thereby preventing related infections. Researchers used MPC polymers for oral bacterial biofilm infections and found that MPC polymers reduced the adhesion of streptococci on oral epithelial cells by 15-30\% (Hirota et al., 2011). Kaneko et al. (2020) later confirmed through in vivo and in vitro experiments that applying the MPC-coated polymer to the surface of bioabsorbable suture could significantly inhibit the adhesion of $S$. aureus and reduce surgical site infections. The anti-adhesion activity of PEG is related to its molecular weight. The amount of bacterial adhesion decreases with increased molecular weight in the range of 300-20,000, and when the molecular weight is 5,000 , the adhesion amount reaches the minimum (Peng et al., 2017).

In addition to hydrophilic coatings, applying antibacterial agents on the surface to kill attached bacteria directly is an effective method to inhibit reversible adhesion. Silver ion has broad-spectrum bactericidal activity and is a commonly used antibacterial coating. Stobie et al. (2009) found that a room temperature processed silver doped perfluoropolyetherurethane coating effectively reduced the adhesion of $S$. aureus on the catheter surface and prevented the formation of biofilms. Silver nanoparticles (Ag NPs) have the unique properties of nanomaterials and the antibacterial properties of silver, making them an ideal material. Researchers revealed that biosynthesized Ag NPs could reduce the adhesion of Klebsiella pneumoniae by $88 \%$ (Rajivgandhi et al., 2020). The antimicrobial peptide is also considered as an effective anti-biofilm coating, which shows better effect than Ag NPs in inhibiting S. aureus adhesion (Kang et al., 2019).

\section{Affecting Pili}

Pili are important surface appendages that enable bacteria to realize movement and adhere to the surfaces. Thus, pili are one of the targets for removing early stage biofilms. Three types of pili are studied (De La Fuente et al., 2007; Burrows, 2012; Arita-Morioka et al., 2018): (1) Type I pili, which are best studied in E. coli, are a functional amyloid primarily responsible for cells' attachment to the surface. (2) Type IV pili are the motility appendage of bacteria that mediate a kind of movement independent of flagella (i.e., twitching motility). The twitching movement plays a critical role in initial adhesion and the development of microcolonies. (3) Curli are the major extracellular surface amyloid fibers that contribute to the initial attachment to a surface and cell-to-cell contact. The drugs that act on type I pili, type IV pili, and curli are introduced in the following section.

The disperse red 15 is a hydroxyl anthraquinone compound that can interfere with FimH, an adhesion factor at the end of the type I pili of E. coli. After the action of disperse red 15, swimming and swarming motilities were inhibited, and the initial adhesion was reduced, resulting in a reduction in biofilm biomass by more than 50\% (Miryala et al., 2020). This result indicated that disperse red 15 could better be used as surface coating to reduce bacterial adhesion and prevent biofilms formation.

Magnesium ions are essential nutrients for the formation of biofilms, which can affect bacterial adhesion and biofilm formation through direct and indirect means (Oknin et al., 2015). However, the promotion of magnesium ions on adhesion is related to its concentration. Researchers found that 0.1 and 0.5 M magnesium ions could inhibit the expression of type IV pili synthesis genes pilV and pilW, thereby reducing type IV pili formation, weakening the initial adhesion of bacteria and inhibiting early stage biofilms formation (Tang et al., 2018).

Ethylene Diamine Tetraacetic Acid (EDTA) is a metal chelating agent. Researchers found that EDTA has the strongest inhibitory effect in the early stage of biofilms formation, but has no biofilm inhibitory effect in the middle and late stages 


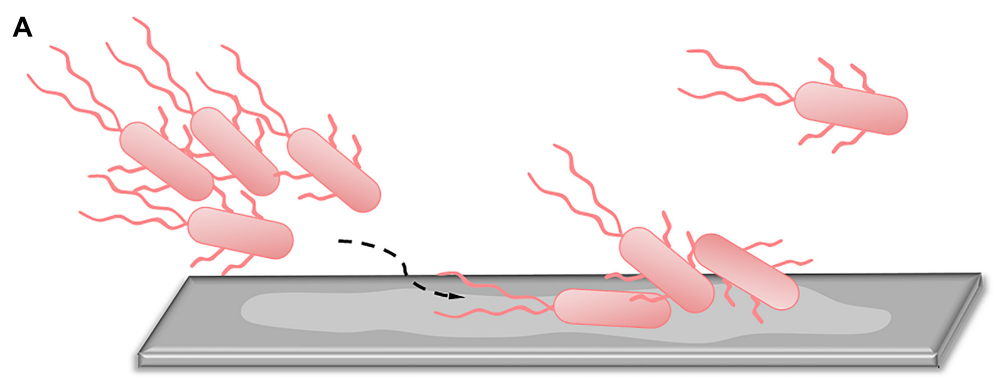

B

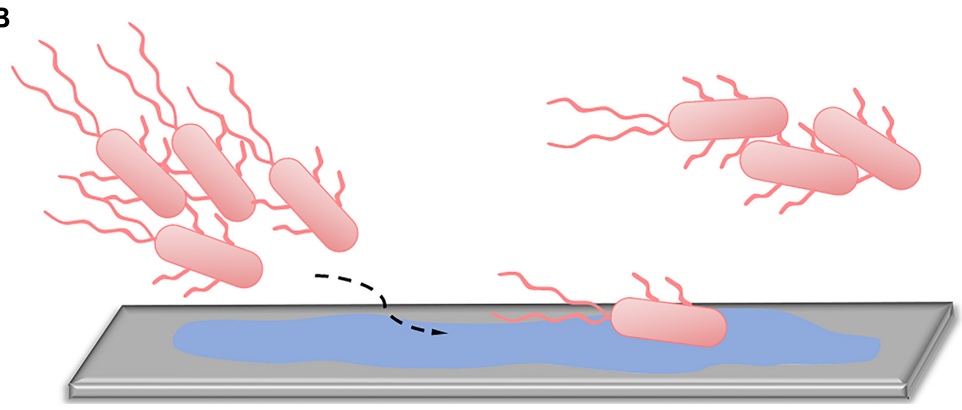

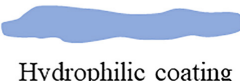

Hydrophilic coating

FIGURE 1 | An alternative approach to reduced reversible adhesion: applying hydrophilic coatings. (A) Without applying hydrophilic coatings, most of the planktonic bacteria can adhere to the surface, and only a small part remains planktonic. (B) After using hydrophilic coatings, due to the repulsion of different charges, only a small part of planktonic bacteria can complete adhesion, while most bacteria are still in planktonic states.

(Chang et al., 2012). EDTA plays an inhibitory role in the early stage by reducing the production of curli to inhibit cell-surface and cell-cell interactions (Chaudhary and Payasi, 2012; Gawad et al., 2017). When combined with ciprofloxacin, gentamicin, and ampicillin, EDTA could reduce the minimal inhibitory concentration of antibiotics and EDTA plus ciprofloxacin treatment had a better therapeutic effect on $P$. aeruginosa biofilms compared with the single treatment (Liu et al., 2017c).

Some bacteria also have type II and type III pili in addition to the above-mentioned pili. Type II pili are related to the pathogenic heterogeneity of Porphyromonas gingivalis (Inaba et al., 2008). Type III pili are an important factor in biofilms formation by Klebsiella pneumoniae, which may be because the pili make the surface of $K$. pneumoniae hydrophobic, thereby promoting bacterial adhesion (Martino et al., 2003). The inhibitors of these two pili are still under investigation.

\section{Affecting Flagella}

The role of flagellar motility and surface adhesion in biofilms formation has been reported in many studies. Flagella are believed to promote bacterial adhesion (Duan et al., 2013): (1) Flagella-mediated motility makes planktonic bacteria move toward target sites, promoting subsequent adherence. (2) Flagella-mediated motility allows bacteria to overcome surface tension and reach the surface. (3) Flagella act as bacterial adhesins to help bacteria attach to the surface. Therefore, the strategy with flagella as target is also an effective method to inhibit early stage biofilms formation.

Agaric acid is a fatty acid naturally produced by certain fungi, such as Polyporus, and can be used as anhidrotic to treat tuberculosis patients with extreme sweating (Bacchi et al., 1969). Studies on Salmonella showed that the formation of biofilms was significantly inhibited after the action of agaric acid because it significantly reduced the expression of flagellar rotation genes. These phenomena inhibit the swimming ability and make bacteria stay in the planktonic stage, thereby preventing initial attachment and reducing early stage biofilms formation (Lories et al., 2020).

\section{INHIBITING EPS PRODUCTION}

Extracellular polymeric substances mediate the irreversible adhesion stage. EPSs allow the long-term attachment of bacteria to surfaces and promote cohesion among bacterial cells, leading to the development of early stage biofilms (Flemming and Wingender, 2010; Karygianni et al., 2020). Therefore, inhibiting EPS production to reduce irreversible adhesion has become an important target (Figure 2). According to matrix components, extracellular anti-EPS molecules fall into three categories: (1) molecules acting on exopolysaccharides, (2) molecules acting on proteins, and (3) molecules acting on eDNA. These molecules destroy the structural integrity of EPS, facilitating the passage of attached bacteria into their vulnerable, planktonic state, and reduce the early stage biofilms formation. The corresponding drugs are described below.

\section{Reducing Exopolysaccharides Production}

Among the components of EPS, the exopolysaccharides are the most abundant and the most thoroughly studied 


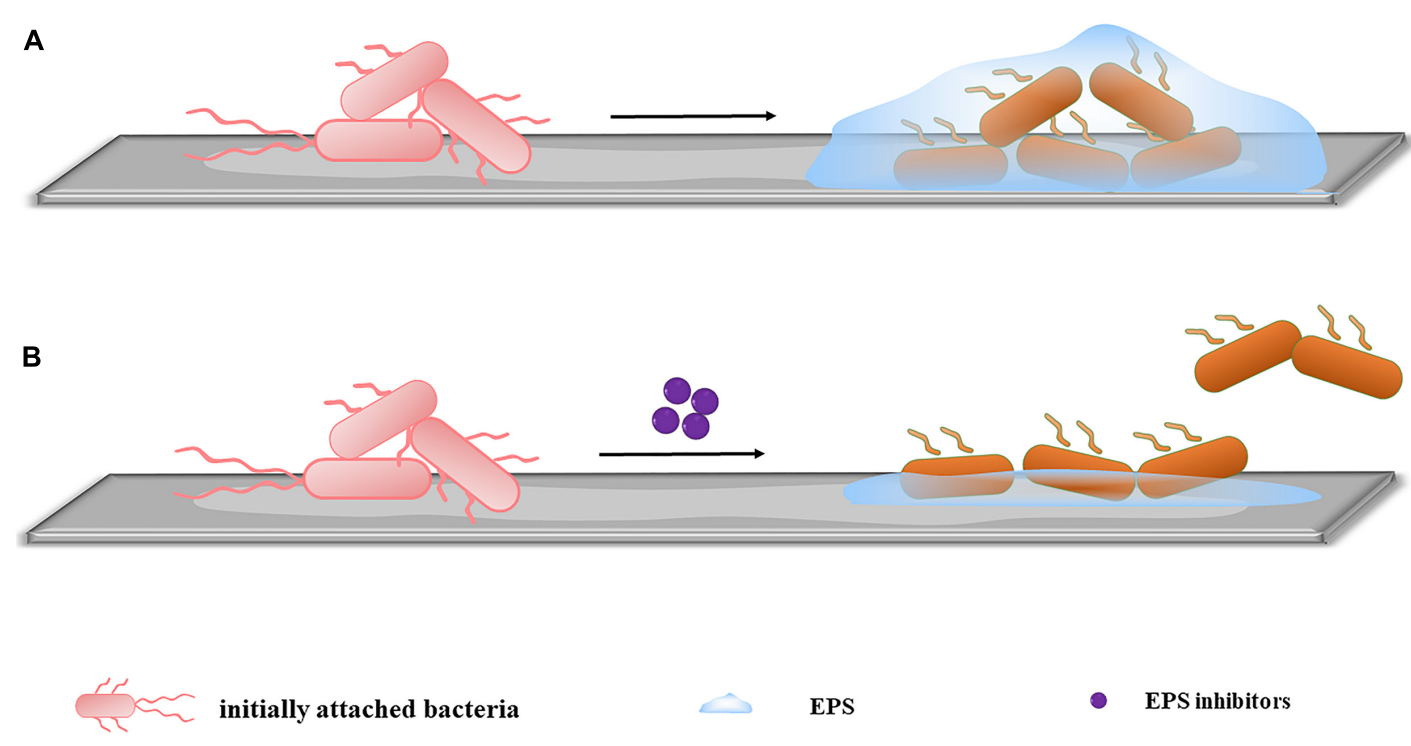

FIGURE 2 | Inhibiting EPS production. (A) When no inhibitors are added, initially attached bacteria bind firmly to the surface by secreting EPS, completing early-stage biofilm formation. (B) After the addition of inhibitors, the EPS secreted by initially attached bacteria is significantly reduced. The irreversible adhesion ability of the bacteria decreases, and some bacteria return to planktonic states, inhibiting early-stage biofilm formation.

component. Different bacteria have different compositions of exopolysaccharides, which are all considered as fundamental matrix for the adhesion and architectural stability of EPS (Sharma et al., 2016; Parai et al., 2020). As molecular glue, the exopolysaccharides allow the initial adhesion of planktonic bacteria on the surface and can fix the bacterial population to increase cell density (Flemming, 2016), becoming an important target in the early stage biofilms removal strategy. At present, most drugs exert their early inhibitory effects by affecting exopolysaccharides and can be divided into chemical drugs, natural components, and probiotics.

\section{Classic Antibiotics}

Ambroxol (ABX) is one of the most widely used expectorant drugs. Previous studies showed that ABX could inhibit biofilms at various stages when used alone (Cataldi et al., 2014) and could enhance the killing effect of Staphylococcus epidermidis biofilms in combination with vancomycin (Zhang et al., 2015). It is presumed that $A B X$ reduces the synthesis of exopolysaccharides and prevents bacterial adhesion to achieve its effect, which was later confirmed in $P$. aeruginosa. After the addition of $\mathrm{ABX}$, the content of alginate decreased (Cheng et al., 2015). The expression of algD gene encoding the ratelimiting enzyme GMD for alginate synthesis was down-regulated. $\operatorname{alg} R$ and $\operatorname{alg} U$ genes, which promote synthesis, were also down-regulated whereas the mucA gene, which inhibits algD expression, was increased. These results showed that ABX influences early stage biofilms by inhibiting the synthesis of exopolysaccharides.

Antibiotics are the most used drug to treat biofilm-related infections. In this article, we take ceftazidime as an example. Ceftazidime is a $\beta$-lactam antibiotic that binds to penicillinbinding proteins to affect cell wall synthesis and reduce bacterial growth. Ceftazidime could inhibit the formation of biofilms of Proteus mirabilis and E. coli (Kwiecińska-Piróg et al., 2013; Sun et al., 2020). In studies about $P$. aeruginosa (Otani et al., 2018), ceftazidime significantly down-regulated the expression of exopolysaccharides Pel- and Psl-related genes pelA and pslA to impair the structural integrity of EPS, leading to decreased adhesion and inhibited biofilms formation. In addition, the twitching motility was suppressed. The twitching motility is mediated by type IV pili and is associated with adhesion. Ceftazidime decreased the mRNA level of lecB gene, which is necessary for motility, but had no effect on the transcription of the pil that encodes pilus components, thus weakening the expression of protein PilHIJK in twitching-related regulatory pathways, restricting twitching capacity, and affecting adhesion.

\section{Plant-Derived Components}

Biofilm-growing bacteria are known to show 10 to 1,000 time-increased resistance to antibiotics than planktonic microorganisms (Dosler and Karaaslan, 2014). The low efficiency of conventional doses of antibiotics and in vivo toxicity of high doses drive researchers toward the discovery of plantderived anti-biofilm molecules. Compared with antibiotics, plant-derived anti-biofilm molecules have the advantages of wide sources, high safety, and low drug resistance, having great potential in controlling biofilms formation. Extracts of Hymenocallis littoralis leaves and tannic acid, the component of Rhus chinensis Mill, could inhibit the formation of S. aureus and $P$. aeruginosa biofilms, respectively (Trentin et al., 2013; Nadaf et al., 2018). Some plant components have been found to inhibit biofilms by inhibiting the initial adhesion of bacteria. Here are some examples.

Thymol is naturally found in the seeds of thyme and oregano, and has a broad-spectrum antimicrobial effect. Studies confirmed 
that thymol can inhibit the biofilms formation of Candida tropicalis and Enterococcus faecalis (Veras et al., 2014; Chatrath et al., 2019). In studies about $P$. aeruginosa and Candida albicans (El et al., 2011; Jafri and Ahmad, 2020), thymol is speculated to affect early stage biofilms by inhibiting adhesion. Thymol can significantly reduce the expression of the pga gene that codes the PGA exopolysaccharide (Wang et al., 2017), the main component of the Actinobacillus pleuropneumoniae biofilm matrix. This phenomenon causes changes in EPS structural components and weakens the irreversible adhesion of bacteria, which is easy to fall of the surface, thereby reducing the early stage biofilms formation. A study about Enterobacter cloacae showed that thymol could also inhibit the curli fimbriae csgABCEFG to affect initial adhesion in addition to affecting exopolysaccharide synthesis genes (Liu et al., 2020a).

Artesunate (AS), a water-soluble derivative of Artemisinin, is used in the treatment of malaria and possesses anti-cancer and anti-inflammatory activities (Kong et al., 2019). In recent years, the combination of AS and tested antibiotics can significantly enhance the antibacterial activity of antibiotics (Cremer et al., 2015). In the study with $P$. aeruginosa, Bao et al. (2019) found that using AS alone could reduce the production of exopolysaccharides, thus playing an inhibitory role in the early stage of biofilms formation. In the experiment, a concentration that had no effect on planktonic bacteria was used. In the early stage biofilms formation process, the Fenton reaction between AS and $\mathrm{Fe}(\mathrm{II})$ produces reactive oxygen species and carbon-centered radicals. No effect on bacteria is observed, but the corresponding decrease in $\mathrm{Fe}(\mathrm{II})$ increases the synthesis of rhamnolipids, competitively inhibits the precursors of polysaccharides, and reduces the production of Psl (Yu S. et al., 2016). The reduction in Psl has a negative effect on irreversible adhesion, thus inhibiting the formation of early stage biofilms. Twitching motility can promote the formation of microcolonies, which is beneficial to biofilms formation. However, excessive twitching movement has a negative effect on the formation of biofilms (Patriquin et al., 2008). Experimental results showed that AS promoted the twitching motility of $P$. aeruginosa PAO1 in a concentration-dependent manner, resulting in the difficult aggregation and attachment of bacteria and inhibited the formation of biofilms.

Phenyllactic acid (PLA) is an organic acid that exists in many plants and food products, such as honey and lactic acid bacteriafermented food, and has a broad-spectrum antibacterial effect (Ning et al., 2017). The researched area found that PLA can also inhibit the formation of bacterial biofilms, such as Listeria monocytogenes (L. monocytogenes) and E. cloacae (Liu et al., 2017a,b). In the study about E. faecalis (Liu et al., 2020b), it was found that the number of bacteria adhering to polyethylene plate and stainless-steel plates decreased significantly after PLA treatment, and that the ability of adhesive bacteria to produce EPSs was also inhibited. Reverse-transcription polymerase chain reaction confirmed that PLA significantly inhibited the expression of EPA polysaccharide synthesis genes, suggesting that PLA could reduce the bacterial adhesion rate and inhibit early stage biofilms development by reducing extracellular polysaccharide synthesis.

\section{Probiotics}

Lactobacillus is one of the probiotic species and can play a potent role in promoting body development, stimulating the immune system, and has an inhibitory effect on the formation of $P$. aeruginosa and Salmonella biofilms (Shokri et al., 2018; Merino et al., 2019). In the study with S. aureus (Melo et al., 2016), it was observed that treatment with Lactobacillus significantly increased the expression of $i c a R$ and decreased the expression of icaA, leading to the inhibition of the synthesis of PIA and affecting the adhesion between bacteria and early stage biofilms formation. Lactobacillus salivarius and Lactobacillus kefiranofaciens can inhibit the expression levels of $g t f B C D$ and $f t f$, respectively, thereby reducing the synthesis of exopolysaccharides, hindering initial adhesion, and inhibiting early stage biofilms formation of Streptococcus mutans (S. mutans) (Wu et al., 2015; Jeong et al., 2018).

\section{Reducing Extracellular Proteins Production}

In general, only proteins that play a structural role have been clearly characterized, and matrix proteins are poorly defined and understood (Tseng et al., 2018). However, matrix proteins have been suggested to promote bacterial adhesion and early stage biofilms accumulation (Matsumoto-Nakano, 2018). For example, in S. aureus, the biofilm-associated protein (BAP) promotes initial attachment and cell-to-cell interaction through mechanisms independent of extracellular polysaccharides. When BAP is inhibited, the abilities of primary attachment and biofilms formation are significantly reduced (Cucarella et al., 2001). Therefore, reducing the production of extracellular proteins is one of the effective methods to control early stage biofilms formation, and D-amino acids and rhamnolipid are believed to exert biofilms inhibition by affecting extracellular proteins.

\section{D-Amino Acids}

D-amino acids, also called unnatural amino acids, are enantiomers with L-amino acids and naturally exist in organisms. Researchers first demonstrated that $6 \mathrm{mg} / \mathrm{L}$ D-tyr could remove biofilms from nylon membrane surfaces (Xu and Liu, 2011). Subsequent studies showed that D-amino acids have an inhibitory effect on the formation of biofilms. For example, a mixture of D-leu and D-try can inhibit the formation of $S$. aureus and $P$. aeruginosa biofilms, and a mixture of D-pro and D-ala can inhibit the formation of S. epidermidis biofilms (Kolodkin-Gal et al., 2010; Ramón-Peréz et al., 2014).

At experimental concentrations, the addition of exogenous D-amino acids has no effect on bacterial growth, but can significantly inhibit the formation of biofilms (Li et al., 2015; She et al., 2015), suggesting that the inhibition of bacterial growth is not the mechanism by which $\mathrm{D}$-amino acids inhibit the formation of biofilms. D-amino acids inhibit biofilms development by reducing initial adhesion.

In $P$. aeruginosa and $S$. aureus, the production of extracellular proteins was significantly reduced after D-amino acids treatment, but had no effect on exopolysaccharides (Hochbaum et al., 2011; Yu C. et al., 2016). D-amino acids are substituted for L-amino acids in a protein (Pundir et al., 2018), and the protein undergoes 
changes in structure, making the protein minimally secreted. This finding suggests that the change in extracellular proteins may be the cause of D-amino acids inhibition of adhesion. Thermodynamic research reported that with the addition of D-tyr, Lewis acid-base interactions are more affected than the overall non-specific interactions (Xing et al., 2015). The Lewis acid-base force is closely related to hydrophilicity, and the change in EPS has a negative effect on the water contact angle (Sheng and $\mathrm{Yu}, 2006$ ). The decrease in the protein/polysaccharide ratio is likely to be the cause of increased hydrophilicity, which further indicates that D-amino acids inhibit adhesion and biofilms formation by reducing extracellular protein synthesis.

Peptidoglycan (PG), the major component of the cell wall, is composed of repeating units of GlcNAc and $\mathrm{N}$-acetylmuramic acid (MurNAc). A short peptide chain terminating in D-alanine is attached to the lactoyl group of MurNAc, and researchers revealed that exogenous $\mathrm{D}$-amino acids could replace $\mathrm{D}$-alanine to integrate into PG (Lam et al., 2009), changing the composition and architecture of PG. The modification of PG affects the cell wall, and the cell wall is one of the important factors mediating initial adhesion, indicating that $\mathrm{D}$-amino acids may inhibit initial adhesion by affecting the cell wall.

\section{Rhamnolipids}

In recent years, rhamnolipids derived from $P$. aeruginosa have emerged as an important group of biosurfactants with several applications, and are considered a substitute for traditional antibacterial agents. Current studies found that rhamnolipids disrupted many bacterial biofilms, and the exogenous addition of rhamnolipids could impede initial adhesion (Dusane et al., 2010). The study on P. aeruginosa biofilm showed that after rhamnolipids treatment, the reduction in protein concentrations was more than twice the reduction in carbohydrate concentrations (Kim et al., 2015). This result was similar to the later finding that strains with high protein content in the biofilm matrix were more susceptible to surfactants than strains with carbohydrate-based matrix (Silva et al., 2017), indicating that rhamnolipids can have a selective interaction of protein to reduce protein contents and affect the early adhesion of bacteria. Rhamnolipids can affect the swarming motility in addition to reducing protein. The swarming motility is a cell density-dependent, flagella-driven process that enables bacteria to move toward favorable environments and adhere. Studies demonstrated that when rhamnolipids were absent, bacteria lost their ability to swarm, which can be supplemented by providing exogenous rhamnolipids (Caiazza et al., 2005; Nickzad et al., 2015). Therefore, reducing the rhamnolipids content in the bacterial population to hinder swarming motility is also an effective method to inhibit early adhesion. Adding rhamnolipids reduces the protein content but promotes swarming motility. Thus, an in-depth study is needed.

\section{Others}

Proteases, which specifically hydrolyze extracellular proteins, may have great ability to control initial adhesion. When bappositive $S$. aureus were treated with proteinase $\mathrm{K}$, the number of bacteria attached to the microtiter plate at the primary stage was significantly reduced (Kumar Shukla and Rao, 2013), indicating that exogenous proteases destroyed the physical stability of the EPS and hampered early adhesion. Later studies showed that protease $\mathrm{K}$ can hydrolyze extracellular proteins and reduce the eDNA content (Shukla and Rao, 2017). Papain and trypsin can digest the fimbrial proteins FimP and FimA (Mugita et al., 2017). eDNA and fimbriae also play an important role in initial adhesion, which further suggests that proteases can be an antiadhesive agent to affect the early stage biofilms formation.

Curcumin is a hydrophobic polyphenolic substance extracted from the dried rhizomes of Turmeric, a plant of the genus Curcuma, and is recognized as a safe food additive. In addition to being a natural food coloring, curcumin is found as an inhibitor of sortase A activity in S. aureus (Hu et al., 2013b). Curcumin can inhibit surface protein production or separate protein from cell walls, thereby reducing the initial adhesion and inhibiting early stage biofilms formation (Park et al., 2005; Hu et al., 2013a).

\section{Reducing eDNA Production}

The content of eDNA is significantly less than those of proteins and exopolysaccharides, and related studies are few. However, eDNA is generally believed to promote initial bacterial adhesion and surface aggregation (Jakubovics and Burgess, 2015). eDNA promotes the adhesion of bacteria to biotic and abiotic surfaces, and its essence may have the following points. First, irreversible adhesion is mediated by Lewis acid-base forces, and thermodynamic analysis showed that the presence of eDNA promotes the acid-base interaction (Das et al., 2010), which is more conducive to the attachment of bacteria on the surface, and has a remarkable promotion effect on the formation of biofilms. Second, eDNA does not exist independently in EPSs and interacts with other biomolecules in the biofilm matrix (Okshevsky et al., 2015). Maintaining the integrity of the EPS structure and facilitating the adhesion between bacteria and surface are important. Researchers found that the removal of eDNA also results in the reduction of exopolysaccharides and proteins ( $\mathrm{Yu}$ et al., 2018). Third, the presence of eDNA widens the adhesion distance, facilitating bacteria to begin irreversible adhesion at a large distance scale (Okshevsky and Meyer, 2015), which remarkably promotes the formation of early stage biofilms. Therefore, reducing eDNA production is also an effective method to inhibit initial adhesion, and current studies confirmed that DNase and reserpine exert early stage biofilms inhibition by affecting eDNA.

\section{DNase}

At present, DNase is the most in-depth studied strategy of removing eDNA, and can be used to decompose eDNA to reduce bacterial adhesion and control the formation of early stage biofilms. Studies showed that after treating L. monocytogenes (Harmsen et al., 2010), Burkholderia pseudomallei (Pakkulnan et al., 2019) and S. aureus (Parastan et al., 2020) with DNase, the bacteria attached to the surface were significantly reduced, and the formation of biofilms were inhibited. The first functional DNase I coating has reduced bacterial adhesion by $95-99 \%$ (Swartjes et al., 2013). However, DNase can easily remove young biofilms and partially inhibit middle-stage biofilms, but 
has no effect on mature biofilms (Okshevsky et al., 2015; Schlafer et al., 2017).

\section{Others}

Reserpine, a drug used to treat hypertension and psychosis, has been recently found to inhibit the formation of $S$. aureus biofilms because it has the same active site as the AtlE protein ligand (Parai et al., 2020). Reserpine competitively inhibits the binding of ligands to AtlE protein, thereby reducing the synthesis and secretion of eDNA (Kerckhoven et al., 2016), resulting in decreased adhesion and inhibiting biofilms formation.

Totarol, a diterpene compound isolated from the totarol tree, has remarkable antibacterial and antioxidant activities. In the study with $S$. aureus biofilms (Guo et al., 2015), the expression levels of the $i c a A$ gene encoding exopolysaccharide synthesis and the cidA gene encoding eDNA synthesis decreased significantly after the action of totarol, and the expression amount of cidA decreased more, indicating that totarol reduces the synthesis of eDNA to inhibit early adhesion.

Researchers found that a biosurfactant can significantly downregulate the expression of $d l t B$ and $c i d A$ genes in $S$. aureus and that the $d l t B$ operon promotes bacterial adhesion (Yan et al., 2019). Among the two adhesion-related genes, cidA expression is more significantly affected than $d l t B$ expression, suggesting that this biosurfactant reduces adhesion by inhibiting eDNA.

\section{INHIBITION OF THE QS SYSTEM}

The QS system confers bacteria as a community to approach the surface in a consistent manner and increase the secretion of EPS, making the attachment firmly, which is beneficial to the formation of early stage biofilms. According to the chemical types of signal molecules, the QS system can be roughly divided into three types (Wu et al., 2020): (1) N-acyl-homoserines (AHLs)mediated QS system, which exists in Gram-negative bacteria; (2) auto-inducing peptide (AIP)-mediated QS system, which exists in Gram-positive bacteria; and (3) autoinducer 2 (AI2)-mediated QS system, which exists in Gram-negative and Gram-positive bacteria. Studies found a QS system mediated by the Pseudomonas Quinolone Signal (PQS) in P. aeruginosa (Li et al., 2020).

Given the important role of QS in early stage biofilms development, the mode targeting at QS has also become an alternative approach to combat undesirable microorganisms. By acting on different steps of the signaling cascade, QS inhibitors can be divided into three categories (Kalia et al., 2019), (1) blocking the generation of signal molecules, (2) preventing the signal molecules from binding to the corresponding receptors, and (3) degrading the generated signal molecules (Figure 3). Different QS inhibitors are described as follows.

\section{Blocking the Generation of Signal Molecules}

Coumarins, a group of heterocyclic compounds present in many natural plants, have a wide range of biological activities such as antiviral and antioxidation properties, and can be used as QS inhibitors to affect the formation of biofilms such as E. coli, $P$. aeruginosa, and $S$. aureus (D'Almeida et al., 2017; Das et al., 2018; Reen et al., 2018). The study about $P$. aeruginosa found that the expression levels of lasI, rhlI, and pqsBCH that encoding signal molecules synthesis was significantly downregulated after the action of $2 \mathrm{mM}$ coumarin, whereas those of receptor genes las $R$ and $p q s R$ remained unchanged (Zhang et al., 2018). As a result, the syntheses of AHL molecules and PQS was hindered, affecting the QS system and reducing the formation of biofilms. Eugenol has similar mechanism of action with coumarins. After treatment with eugenol and its nanoemulsion at a concentration of $0.2 \mathrm{mg} / \mathrm{mL}$, the expression levels of QS synthase genes lasI and rhlI were inhibited. The inhibition effect led to a decrease in the production of 3-oxo-C12-HSL and C4-HSL, which affected swarming motility and biofilms formation of $P$. aeruginosa (Lou et al., 2019).

Salicylic acid, the bulk drug used to synthesize aspirin, is also a strong inhibitor of AHL and interferes with the production of AHL by binding to the substrates needed for its production (Shaaban et al., 2019). Trans-cinnamaldehyde interacts with the substrate binding site of LasI to inhibit AHL production (Chang et al., 2014; Shaaban et al., 2019). Triclosan reduces the production of AHL and inhibits the QS system by inhibiting the enoyl-acyl carrier protein reductase which is an essential intermediate in AHL biosynthesis (Basavaraju et al., 2016).

\section{Preventing Signaling Molecules From Binding to Corresponding Receptors}

Furan compounds are originally discovered in the red marine alga Delisea pulchra. Given their similarity in structure with AHLs, they can replace AHLs to bind with corresponding LasR receptors and inhibit the QS system (Kim et al., 2012; Kalia, 2013). This competitive inhibitory effect is dependent on dose. Thus, the side effects of high doses should be considered when developing furan compounds as QS inhibitors. (5Z)-4-bromo5-(bromomethylene)-3-butyl-2(5H)-furanone has been shown to act as antagonist of AHL and AI-2 QS signals in many organisms (Kalia et al., 2019). At concentrations of 2.0 and $4.0 \mu \mathrm{g} / \mathrm{mL}$, furanone C-30 could inhibit exopolysaccharide genes $f t f$ and $g t f B$ and extracellular protein gene $g b p B$ in the biofilm of $S$. mutans without affecting the growth of planktonic bacteria (He et al., 2012), thereby reducing the initial adhesion and inhibiting the formation of biofilms. Chlorogenic acid (CA) (Deryabin et al., 2019), flavonoids (Liu et al., 2017d; Abinaya and Gayathri, 2019), and cinnamaldehyde (Li et al., 2018) have similar mechanisms of action with furan compounds. After the action of CA, the production of rhamnolipid was inhibited (Wang et al., 2019), further affecting the early stage biofilms formation of $P$. aeruginosa.

In addition, the apolipoprotein B can prevent AIP1 from binding to the receptor and inhibit the QS system of methicillinresistant $S$. aureus (Peterson et al., 2008).

\section{Degrading Generated Signal Molecules}

In the QS system, it is critical for AHL molecules to reach a threshold concentration. Therefore, if AHLs can be degraded 
A

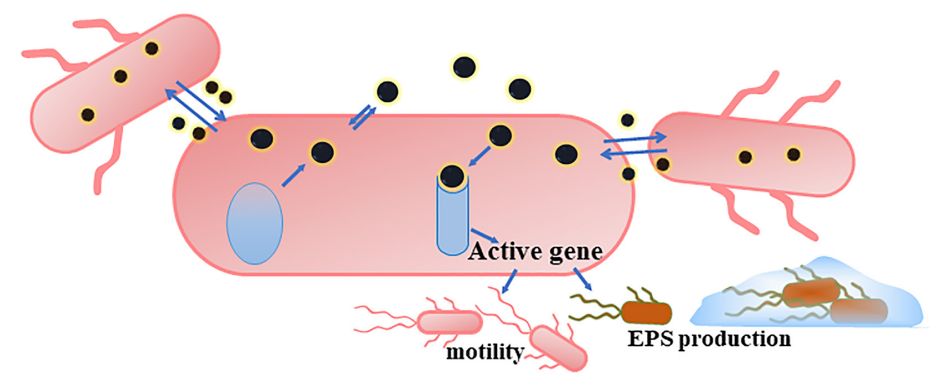

B

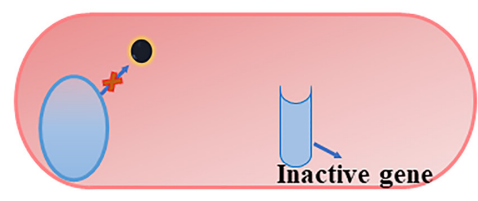

C

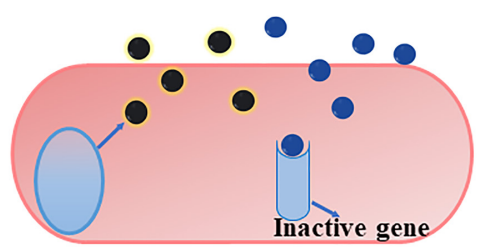

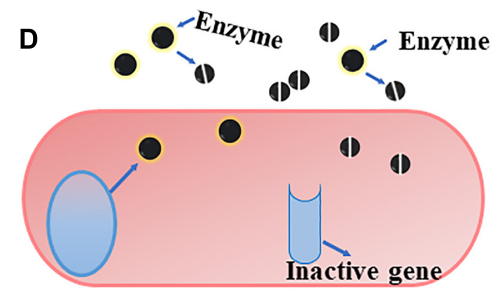

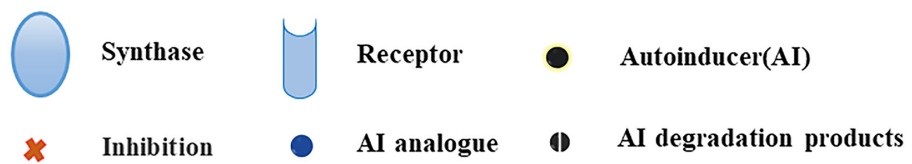

FIGURE 3 | An overview of QS system (A) and the three main strategies to combat it. (B) Blocking the generation of Al. The inhibition of some of synthase can affect the production of more than one signal. (C) Preventing Al from binding to the corresponding receptors. The use of Al analogs can competitively inhibit the binding of Al to the receptor, and the analogs themselves have no pharmacological activity, so they cannot activate the corresponding gene expression and the QS mechanism is ceased. (D) Degrading the generated Al. Degrading the Al with the corresponding enzyme makes it unable to reach the threshold concentration and the degradation products cannot bind to the receptor, inhibiting the QS system.

to make it unable to reach the threshold concentration, the formation of biofilms is remarkably weakened. According to the chemical structure of AHLs, three action sites, namely, lactonase site, acyltransferase site, and oxidoreductase site, can decompose AHLs (Huang et al., 2016). The degradation of AHL is largely regulated by AHL acyltransferase and AHL lactonase, which hydrolyze the bond and HSL ring, respectively (Brackman and Coenye, 2015; Haque et al., 2018), and degrade AHLs to inhibit the QS system.

\section{TARGETING c-di-GMP SIGNALING}

The c-di-GMP signaling plays critical roles during the biofilms formation. Flagellar motility and EPS secretion, which are partly regulated by c-di-GMP signaling and facilitate early stage biofilms development. Thus, blocking c-di-GMP signal transduction is important to inhibit the early stage biofilms. The c-di-GMP-mediated signaling pathway consists of four parts (Boyd and O'Toole, 2012): (1) DGCs that promote the synthesis of c-di-GMP, (2) effector molecules combined with c-di-GMP, (3) downstream targets regulated by effector molecules, and (4) PDEs that degrade c-di-GMP. Among them, the synthesis and degradation of c-di-GMP by DGCs and PDEs are the core of the whole signaling pathway (Figure 4). The following describes the corresponding methods based on these two targets.

\section{Targeting DGCs}

Controlling endogenous synthesis of c-di-GMP is more efficient than directly acting on the downstream targets of c-di-GMP. A glycosylated triterpenoid saponin purified from extracts of garden pea is identified as the first effective inhibitor of DGC, and Papulacandin B and $N$-(4-anilinophenyl) benzamide are subsequently demonstrated as inhibitors (Opoku-Temeng and Sintim, 2017). Considering that the catalytic domain of DGCs is similar to the catalytic domain of mammalian adenylyl cyclases, and $2^{\prime}\left(3^{\prime}\right)-O-(N$-methylanthraniloyl) (MANT)- and $2^{\prime}, 3^{\prime}$-O-(2,4,6-trinitrophenyl) (TNP)-substituted nucleotides are potent adenylyl and guanylyl cyclase inhibitors, researchers tested various MANT- and TNP- substituted nucleotides and found that MANT-GTP, MANT-GTP $\gamma$ S, and TNP-GTP acted as potent inhibitors against E. coli DGCs (Spangler et al., 2011).

\section{Targeting PDEs}

Stimulating the activity of PDE keeps the intracellular c-diGMP at a low concentration, which has a negative effect on biofilms formation. Endogenously produced nitric oxide (NO) is a signaling molecule that reduces the concentration of $\mathrm{c}$-diGMP in the population by stimulating the activity of PDE (Vuotto and Donelli, 2019). In clinical trials, the inhalation of a low dose of NO $(10 \mathrm{ppm})$ significantly reduced $P$. aeruginosa biofilm aggregation in cystic fibrosis patients (Howlin et al., 2017). The application of NO-releasing chitosan dressings to 


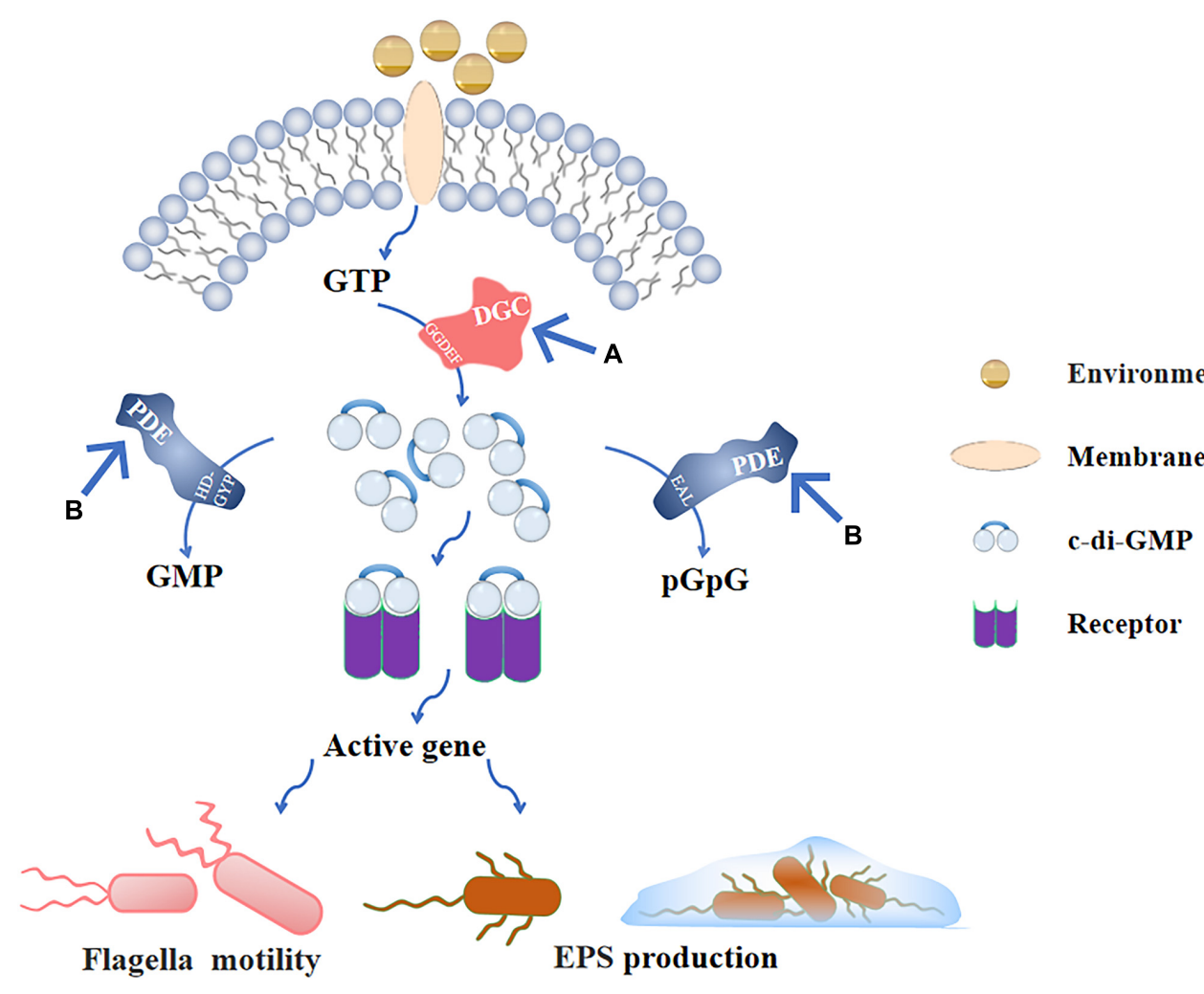

FIGURE 4 | C-di-GMP signaling pathway and (A), (B) are the main inhibitory modes. After the environmental signals are combined with the receptor on the membrane, GTP is produced in the cell. GTP is catalyzed by the GGDEF domain in DGC to form c-di-GMP, and produced c-di-GMP binds to the intracellular receptor to activate the corresponding gene expression and regulate flagellar movement and EPS production; PDE also exists in the cell, and the EAL domain and HD-GYP domain can, respectively, hydrolyze c-di-GMP into pGpG and GMP to inactivate it. (A) Inhibiting the activity of DGC prevents GTP from producing C-di-GMP, so that downstream genes cannot be regulated. (B) Stimulating the activity of PDE to decrease the intracellular C-di-GMP levels that is negatively affects the formation of early stage biofilms.

S. aureus-infected wounds in mice could enhance biofilm dispersal (Choi et al., 2020). Here, we emphasize that the low concentration of $\mathrm{NO}$ can trigger biofilm dispersal because a high concentration can promote the biofilm formation of some bacteria, such as $P$. aeruginosa and Nitrosomonas europaea (Arora et al., 2015). This phenomenon may be because a high concentration of $\mathrm{NO}$ causes anaerobic environments, and forming biofilms in anaerobic environments can be used as a stress defense mechanism (Cutruzzolà and Frankenberg-Dinkel, 2016). Therefore, the critical concentration should be determined before using $\mathrm{NO}$ as an antibacterial agent.

\section{CONCLUSION}

Researches about biofilms has basically begun in the 1970s (Gebreyohannes et al., 2019). Once the biofilms mature, they are difficult to eradicate due to the EPS barrier function and the efflux pump system, causing serious harm. Thus, intervening in the early stage of biofilms formation can be a solution. The inhibition of early stage biofilms formation can be accomplished by affecting the adhesion of bacteria. Reducing bacterial adhesion can be divided into two points. One is to prevent bacteria from approaching the surface, which is mainly by changing the surface properties or reducing the movement of bacteria, and the other is to reduce the production of EPSs.

Researches on the inhibition of biofilm formation based on hydrophilic coatings changing the properties of the surface and antimicrobial coatings killing the attached bacteria have been relatively mature, but these methods are suitable for biofilms formation of related equipment and implants. Using molecular drugs to inhibit early stage biofilms formation from internal mechanisms is a research hotspot. The movement ability and EPS secretion of bacteria are important factors that affect the formation of early stage biofilms. At the same time, the QS system and c-di-GMP signaling pathway regulate these two behaviors, so early stage biofilms inhibitors can be divided into: (1) reducing bacterial movement ability, (2) inhibiting EPS production, (3) interfering with QS system, and (4) destroying c-di-GMP signal pathway. Inhibitors of the same type can also exert corresponding effects through different pathways, for example, with the same extracellular protein inhibitors, $\mathrm{D}$-amino acids can reduce protein production, rhamnolipids can bind to the protein, and proteases can hydrolyze the protein. Early stage biofilms are fragile, have no 3D structures yet, and are relatively easy to be removed. Early stage biofilms treatments combined with antibiotics have 
the potential to achieve better therapeutic effects compared to monotherapy, as exemplified by Zhang et al. (2015) and Liu et al. (2017c). Thus, early intervention is necessary.

To date, efforts have already been made in the biofilms field, but current researches on the early inhibition of biofilms have not achieved effective breakthroughs due to two main reasons. First, current techniques for detecting early stage biofilms infections are immature. When infections caused by biofilms are diagnosed, they often develop to the mature biofilm, and this presents a substantial problem in having the opportunity to treat infections at the early stage biofilm progression in the first place. Second, clinical studies are lacking. The differences between in vitro and in vivo experiments are large, and current in vitro assays cannot effectively guarantee the outcomes in clinical practices. In vitro experiments can only preliminarily prove that drugs have therapeutic effects. When the body is infected with biofilms, it will undergo complex changes, which cannot be effectively simulated by in vitro experiments. These phenomena hinder the progress toward the further application for some types of molecules.

\section{REFERENCES}

Abinaya, M., and Gayathri, M. (2019). Inhibition of biofilm formation, quorum sensing activity and molecular docking study of isolated 3, 5, 7Trihydroxyflavone from Alstonia scholaris leaf against P.aeruginosa. Bioorg Chem. 87, 291-301. doi: 10.1016/j.bioorg.2019.03.050

Arita-Morioka, K. I., Yamanaka, K., Mizunoe, Y., Tanaka, Y., Ogura, T., and Sugimoto, S. (2018). Inhibitory effects of Myricetin derivatives on curlidependent biofilm formation in Escherichia coli. Sci. Rep. 8:8452. doi: 10.1038/ s41598-018-26748-z

Arora, D. P., Hossain, S., Xu, Y., and Boon, E. M. (2015). Nitric Oxide regulation of bacterial biofilms. Biochemistry 54, 3717-3728. doi: 10.1021/bi501476n

Bacchi, C. J., Ciaccio, E. I., and Koren, L. E. (1969). Effects of some antitumor agents on growth and glycolytic enzymes of the flagellate Crithidia. J. Bacteriol. 98, 23-28. doi: 10.1128/jb.98.1.23-28.1969

Bao, L., Guo, J., Feng, L., Zhou, X., and Lu, Q. (2019). Efficacy of artesunate against Pseudomonas aeruginosa biofilm mediated by iron. Biomed. Res. Int 2019:4810217. doi: 10.1155/2019/4810217

Baraquet, C., Murakami, K., Parsek, M. R., and Harwood, C. S. (2012). The FleQ protein from Pseudomonas aeruginosa functions as both a repressor and an activator to control gene expression from the pel operon promoter in response to c-di-GMP. Nucleic Acids Res. 40, 7207-7218. doi: 10.1093/nar/gks384

Basavaraju, M., Sisnity, V. S., Palaparthy, R., and Addanki, P. K. (2016). Quorum quenching: signal jamming in dental plaque biofilms. J. Dent. Sci. 11, 349-352. doi: 10.1016/j.jds.2016.02.002

Boyd, C. D., and O'Toole, G. A. (2012). Second messenger regulation of biofilm formation: breakthroughs in understanding c-di-GMP effector systems. Annu. Rev. Cell. Dev. Biol. 28, 439-462. doi: 10.1146/annurev-cellbio-101011-155705

Brackman, G., and Coenye, T. (2015). Quorum sensing inhibitors as anti-biofilm agents. Curr. Pharm. Des. 21, 5-11. doi: 10.2174/1381612820666140905114627

Burrows, L. L. (2012). Pseudomonas aeruginosa twitching motility: type IV pili in action. Annu. Rev. Microbiol. 66, 493-520. doi: 10.1146/annurev-micro092611-150055

Caiazza, N. C., Shanks, R. M., and O’Toole, G. A. (2005). Rhamnolipids modulate swarming motility patterns of Pseudomonas aeruginosa. J. Bacteriol. 187, 73517361. doi: 10.1128/jb.187.21.7351-7361.2005

Cataldi, M., Sblendorio, V., Leo, A., and Piazza, O. (2014). Biofilm-dependent airway infections: a role for ambroxol? Pulm. Pharmacol. Ther. 28, 98-108. doi: 10.1016/j.pupt.2013.11.002

Chang, C. Y., Krishnan, T., Wang, H., Chen, Y., Yin, W., Chong, Y. M., et al. (2014). Non-antibiotic quorum sensing inhibitors acting against $\mathrm{N}$-acyl homoserine lactone synthase as druggable target. Sci. Rep. 4:7245. doi: 10.1038/srep07245
Therefore, future researches should focus on the establishment of early stage biofilms infection models, in vivo experiments, and improvement of detection technology.

\section{AUTHOR CONTRIBUTIONS}

JF drafted the manuscript. YZ and SL were responsible for preparing the tables and figures in the manuscript. WZ, JL, HL, FX, HT, GP, LZ, and SC reviewed the manuscript. HF conceptualized the content of the manuscript. All authors contributed to the article and approved the submitted version.

\section{ACKNOWLEDGMENTS}

The authors thank Quanjin Liu, Haibo Dou, and Yang Chen of Sichuan Agricultural University, China for improving the manuscript.

Chang, Y., Gu, W., and McLandsborough, L. (2012). Low concentration of ethylenediaminetetraacetic acid (EDTA) affects biofilm formation of Listeria monocytogenes by inhibiting its initial adherence. Food Microbiol. 29, 10-17. doi: 10.1016/j.fm.2011.07.009

Chatrath, A., Gangwar, R., Kumari, P., and Prasad, R. (2019). In vitro anti-biofilm activities of citral and thymol against candida tropicalis. J. Fungi (Basel) 5:13. doi: 10.3390/jof5010013

Chaudhary, M., and Payasi, A. (2012). Role of EDTA and CSE1034 in curli formation and biofilm eradication of Klebsiella pneumoniae: a comparison with other drugs. J. Antibiot (Tokyo) 65, 631-633. doi: 10.1038/ja.2012.82

Cheng, C., Du, L., Yu, J., Lu, Q., He, Y., and Ran, T. (2015). Ciprofloxacin plus erythromycin or ambroxol ameliorates endotracheal tube-associated Pseudomonas aeruginosa biofilms in a rat model. Pathol. Res. Pract. 211, 982-988. doi: 10.1016/j.prp.2015.10.003

Choi, M., Hasan, N., Cao, J., Lee, J., Hlaing, S. P., and Yoo, J. W. (2020). Chitosan-based nitric oxide-releasing dressing for anti-biofilm and in vivo healing activities in MRSA biofilm-infected wounds. Int. J. Biol. Macromol. 142, 680-692. doi: 10.1016/j.ijbiomac.2019.10.009

Cremer, K. D., Lanckacker, E., Cools, T. L., Bax, M., Brucker, K. D., Cos, P., et al. (2015). Artemisinins, new miconazole potentiators resulting in increased activity against Candida albicans biofilms. Antimicrob. Agents Chemother. 59, 421-426. doi: 10.1128/aac.04229-14

Cucarella, C., Solano, C., Valle, J., Amorena, B., Lasa, I., and Penadés, J. R. (2001). Bap, a Staphylococcus aureus surface protein involved in biofilm formation. J. Bacteriol. 183, 2888-2896. doi: 10.1128/jb.183.9.2888-2896.2001

Cutruzzolà, F., and Frankenberg-Dinkel, N. (2016). Origin and impact of nitric oxide in Pseudomonas aeruginosa biofilms. J. Bacteriol. 198, 55-65. doi: 10.1128/ jb.00371- 15

D’Almeida, R. E., Molina, R. D. I., Viola, C. M., Luciardi, M. C., Nieto Peñ;alver, C., Bardón, A., et al. (2017). Comparison of seven structurally related coumarins on the inhibition of Quorum sensing of Pseudomonas aeruginosa and Chromobacterium violaceum. Bioorg Chem. 73, 37-42. doi: 10.1016/j. bioorg.2017.05.011

Das, T., Das, M. C., Das, A., Bhowmik, S., Sandhu, P., Akhter, Y., et al. (2018). Modulation of S. aureus and P. aeruginosa biofilm: an in vitro study with new coumarin derivatives. World J. Microbiol. Biotechnol. 34:170. doi: 10.1007/ s11274-018-2545-1

Das, T., Sharma, P. K., Busscher, H. J., van der Mei, H. C., and Krom, B. P. (2010). Role of extracellular DNA in initial bacterial adhesion and surface aggregation. Appl. Environ. Microbiol. 76, 3405-3408. doi: 10.1128/aem.03119-09

De La Fuente, L., Montanes, E., Meng, Y., Li, Y., Burr, T. J., Hoch, H. C., et al. (2007). Assessing adhesion forces of type I and type IV pili of Xylella fastidiosa 
bacteria by use of a microfluidic flow chamber. Appl. Environ. Microbiol. 73, 2690-2696. doi: 10.1128/aem.02649-06

Deryabin, D., Galadzhieva, A., Kosyan, D., and Duskaev, G. (2019). Plant-derived inhibitors of AHL-mediated quorum sensing in bacteria: modes of action. Int. J. Mol. Sci. 20:5588. doi: 10.3390/ijms20225588

Dosler, S., and Karaaslan, E. (2014). Inhibition and destruction of Pseudomonas aeruginosa biofilms by antibiotics and antimicrobial peptides. Peptides 62, 32-37. doi: 10.1016/j.peptides.2014.09.021

Duan, Q., Zhou, M., Zhu, L., and Zhu, G. (2013). Flagella and bacterial pathogenicity. J. Basic Microbiol. 53, 1-8. doi:10.1002/jobm.2011 00335

Dusane, D. H., Nancharaiah, Y. V., Zinjarde, S. S., and Venugopalan, V. P. (2010). Rhamnolipid mediated disruption of marine Bacillus pumilus biofilms. Colloids Surf. B Biointerfaces 81, 242-248. doi: 10.1016/j.colsurfb.2010.07.013

El, A. S., Ibnsouda, K. S., Latrache, H., Zineb, G., Mouradi, H., and Remmal, A. (2011). Carvacrol and thymol components inhibiting Pseudomonas aeruginosa adherence and biofilm formation. African J. Microbiol. Res. 5, 3229-3232. doi: $10.5897 /$ ajmr 11.275

Flemming, H. C. (2016). EPS-Then and Now. Microorganisms 4:41. doi: 10.3390/ microorganisms 4040041

Flemming, H. C., and Wingender, J. (2010). The biofilm matrix. Nat. Rev. Microbiol. 8, 623-633. doi: 10.1038/nrmicro2415

Gawad, W. E., Helmy, O. M., Tawakkol, W. M., and Hashem, A. M. (2017). Effect of EDTA on biofilm formation and antibiotic susceptibility of multidrug resistant uropathogenic Escherichia coli clinical isolates in Egypt. African J. Microbiol. Res. 11, 1445-1458. doi: 10.5897/ajmr2017.8700

Gebreyohannes, G., Nyerere, A., Bii, C., and Sbhatu, D. B. (2019). Challenges of intervention, treatment, and antibiotic resistance of biofilm-forming microorganisms. Heliyon. 5:e02192. doi: 10.1016/j.heliyon.2019.e02192

Girish, V. M., Liang, H., Aguilan, J. T., Nosanchuk, J. D., Friedman, J. M., and Nacharaju, P. (2019). Anti-biofilm activity of garlic extract loaded nanoparticles. Nanomedicine 20:102009. doi: 10.1016/j.nano.2019.04.012

Gu, H., Lee, S. W., Carnicelli, J., Jiang, Z., and Ren, D. (2019). Antibiotic susceptibility of Escherichia coli cells during early-stage biofilm formation. J. Bacteriol. 201, e00034-e00119. doi: 10.1128/jb.00034-19

Guo, N., Zhao, X., Li, W., Shi, C., Meng, R., Liu, Z., et al. (2015). The synergy of berberine chloride and totarol against Staphylococcus aureus grown in planktonic and biofilm cultures. J. Med. Microbiol. 64, 891-900. doi: 10.1099/ jmm.0.000106

Hall, C. W., and Mah, T. F. (2017). Molecular mechanisms of biofilm-based antibiotic resistance and tolerance in pathogenic bacteria. FEMS Microbiol. Rev. 41, 276-301. doi: 10.1093/femsre/fux010

Haque, S., Ahmad, F., Dar, S. A., Jawed, A., Mandal, R. K., Wahid, M., et al. (2018). Developments in strategies for Quorum Sensing virulence factor inhibition to combat bacterial drug resistance. Microb. Pathog. 121, 293-302. doi: 10.1016/j. micpath.2018.05.046

Harmsen, M., Lappann, M., Knochel, S., and Molin, S. (2010). The role of extra-cellular DNA during biofilm formation of Listeria monocytogenes. Appl. Environ. Microbiol. 76, 2271-2279. doi: 10.1128/aem.02361-09

He, Z., Wang, Q., Hu, Y., Liang, J., Jiang, Y., Ma, R., et al. (2012). Use of the quorum sensing inhibitor furanone C-30 to interfere with biofilm formation by Streptococcus mutans and its luxS mutant strain. Int. J. Antimicrob. Agents 40, 30-35. doi: 10.1016/j.ijantimicag.2012.03.016

Hirota, K., Yumoto, H., Miyamoto, K., Yamamoto, N., Murakami, K., Hoshino, Y., et al. (2011). MPC-polymer reduces adherence and biofilm formation by oral bacteria. J. Dent. Res. 90, 900-905. doi: 10.1177/0022034511402996

Hochbaum, A. I., Kolodkin-Gal, I., Foulston, L., Kolter, R., Aizenberg, J., and Losick, R. (2011). Inhibitory effects of D-amino acids on Staphylococcus aureus biofilm development. J. Bacteriol. 193, 5616-5622. doi: 10.1128/jb.055 34-11

Howlin, R. P., Cathie, K., Hall-Stoodley, L., Cornelius, V., Duignan, C., Allan, R. N., et al. (2017). Low-Dose Nitric Oxide as targeted anti-biofilm adjunctive therapy to treat chronic Pseudomonas aeruginosa infection in cystic fibrosis. Mol. Ther. 25, 2104-2116. doi: 10.1016/j.ymthe.2017.06.021

Hu, P., Huang, P., and Chen, M. (2013b). Curcumin reduces Streptococcus mutans biofilm formation by inhibiting sortase A activity. Arch. Oral. Biol. 58, 13431348. doi: 10.1016/j.archoralbio.2013.05.004
Hu, P., Huang, P., and Chen, W. (2013a). Curcumin inhibits the Sortase A activity of the Streptococcus mutans UA159. Appl. Biochem. Biotechnol. 171, 396-402. doi: 10.1007/s12010-013-0378-9

Huang, J., Shi, Y., Zeng, G., Gu, Y., Chen, G., Shi, L., et al. (2016). Acylhomoserine lactone-based quorum sensing and quorum quenching hold promise to determine the performance of biological wastewater treatments: an overview. Chemosphere 157, 137-151. doi:10.1016/j.chemosphere.2016. 05.032

Inaba, H., Nakano, K., Kato, T., Nomura, R., Kawai, S., Kuboniwa, M., et al. (2008). Heterogenic virulence and related factors among clinical isolates of Porphyromonas gingivalis with type II fimbriae. Oral Microbiol. Immunol. 23, 29-35. doi: 10.1111/j.1399-302X.2007.00386.x

Jafri, H., and Ahmad, I. (2020). Thymus vulgaris essential oil and thymol inhibit biofilms and interact synergistically with antifungal drugs against drug resistant strains of Candida albicans and Candida tropicalis. J. Mycol. Med. 30:100911. doi: 10.1016/j.mycmed.2019.100911

Jakubovics, N. S., and Burgess, J. G. (2015). Extracellular DNA in oral microbial biofilms. Microbes Infect. 17, 531-537. doi:10.1016/j.micinf.2015. 03.015

Jenal, U., Reinders, A., and Lori, C. (2017). Cyclic di-GMP: second messenger extraordinaire. Nat. Rev. Microbiol. 15, 271-284. doi: 10.1038/nrmicro.20 16.190

Jeong, D., Kim, D. H., Song, K. Y., and Seo, K. H. (2018). Antimicrobial and anti-biofilm activities of Lactobacillus kefiranofaciens DD2 against oral pathogens. J. Oral. Microbiol. 10:1472985. doi:10.1080/20002297.2018.14 72985

Kalia, V. C. (2013). Quorum sensing inhibitors: an overview. Biotechnol. Adv. 31, 224-245. doi: 10.1016/j.biotechadv.2012.10.004

Kalia, V. C., Patel, S. K. S., Kang, Y. C., and Lee, J. K. (2019). Quorum sensing inhibitors as antipathogens: biotechnological applications. Biotechnol. Adv. 37, 68-90. doi: 10.1016/j.biotechadv.2018.11.006

Kaneko, T., Saito, T., Shobuike, T., Miyamoto, H., Matsuda, J., Fukazawa, K., et al. (2020). 2-Methacryloyloxyethyl phosphorylcholine polymer coating inhibits bacterial adhesion and biofilm formation on a suture: an in vitro and in vivo study. Biomed. Res. Int. 2020:5639651. doi: 10.1155/2020/5639651

Kang, J., Dietz, M. J., and Li, B. (2019). Antimicrobial peptide LL-37 is bactericidal against Staphylococcus aureus biofilms. PLoS One. 14:e0216676. doi: 10.1371/ journal.pone. 0216676

Karygianni, L., Ren, Z., Koo, H., and Thurnheer, T. (2020). Biofilm matrixome: extracellular components in structured microbial communities. Trends Microbiol. 28, 668-681. doi: 10.1016/j.tim.2020.03.016

Kerckhoven, M. V., Hotterbeekx, A., Lanckacker, E., Moons, P., Lammens, C., Kerstens, M., et al. (2016). Characterizing the in vitro biofilm phenotype of Staphylococcus epidermidis isolates from central venous catheters. J. Microbiol. Methods 127, 95-101. doi: 10.1016/j.mimet.2016.05.009

Kim, L. H., Jung, Y., Yu, H. W., Chae, K. J., and Kim, I. S. (2015). Physicochemical interactions between rhamnolipids and Pseudomonas aeruginosa biofilm layers. Environ. Sci. Technol. 49, 3718-3726. doi: 10.1021/es505803c

Kim, S. G., Yoon, Y. H., Choi, J. W., Rha, K. S., and Park, Y. H. (2012). Effect of furanone on experimentally induced Pseudomonas aeruginosa biofilm formation: in vitro study. Int. J. Pediatr. Otorhinolaryngol. 76, 1575-1578. doi: 10.1016/j.ijporl.2012.07.015

Kolodkin-Gal, I., Romero, D., Cao, S., Clardy, J., Kolter, R., and Losick, R. (2010). D-amino acids trigger biofilm disassembly. Science 328, 627-629. doi: 10.1126/ science. 1188628

Kong, Z., Liu, R., and Cheng, Y. (2019). Artesunate alleviates liver fibrosis by regulating ferroptosis signaling pathway. Biomed. Pharmacother. 109, 20432053. doi: 10.1016/j.biopha.2018.11.030

Kumar Shukla, S., and Rao, T. S. (2013). Dispersal of Bap-mediated Staphylococcus aureus biofilm by proteinase K. J. Antibiot (Tokyo). 66, 55-60. doi: 10.1038/ja. 2012.98

Kwiecińska-Piróg, J., Bogiel, T., and Gospodarek, E. (2013). Effects of ceftazidime and ciprofloxacin on biofilm formation in Proteus mirabilis rods. J. Antibiot (Tokyo). 66, 593-597. doi: 10.1038/ja.2013.59

Lam, H., Oh, D. C., Cava, F., Takacs, C. N., Clardy, J., de Pedro, M. A., et al. (2009). $\mathrm{D}$-amino acids govern stationary phase cell wall remodeling in bacteria. Science 325, 1552-1555. doi: 10.1126/science. 1178123 
Lee, D. J., Jo, A. R., Jang, M. C., Nam, J., Choi, H. J., Choi, G. W., et al. (2018). Analysis of two quorum sensing-deficient isolates of Pseudomonas aeruginosa. Microb. Pathog. 119, 162-169. doi:10.1016/j.micpath.2018. 04.014

Li, H., Ye, Y., Ling, N., Wu, Q., and Zhang, J. (2015). Inhibitory effects of d-tryptophan on biofilm development by the foodborne Cronobacter sakazakii. Int. Dairy J. 49, 125-129. doi: 10.1016/j.idairyj.2015.05.001

Li, T., Wang, D., Liu, N., Ma, Y., Ding, T., Mei, Y., et al. (2018). Inhibition of quorum sensing-controlled virulence factors and biofilm formation in Pseudomonas fluorescens by cinnamaldehyde. Int. J. Food Microbiol. 269, 98106. doi: 10.1016/j.ijfoodmicro.2018.01.023

Li, W., Zeng, T., Xie, X., Shi, Q., and Li, C. (2020). Inhibition of the pqsABCDE and $\mathrm{pqsH}$ in the pqs quorum sensing system and related virulence factors of the Pseudomonas aeruginosa PAO1 strain by farnesol. Int. Biodeterioration Biodegrad. 151:104956. doi: 10.1016/j.ibiod.2020.104956

Liu, F., Du, L., Zhao, T., Zhao, P., and Doyle, M. P. (2017a). Effects of phenyllactic acid as sanitizing agent for inactivation of Listeria monocytogenes biofilms. Food Control. 78, 72-78. doi: 10.1016/j.foodcont.2017.02.050

Liu, F., Wang, F., Du, L., Zhao, T., Doyle, M. P., Wang, D., et al. (2017b). Antibacterial and antibiofilm activity of phenyllactic acid against Enterobacter cloacae. Food Control 84, 442-448. doi:10.1016/j.foodcont.2017. 09.004

Liu, Z., Lin, Y., Lu, Q., Li, F., Yu, J., Wang, Z., et al. (2017c). In vitro and in vivo activity of EDTA and antibacterial agents against the biofilm of mucoid Pseudomonas aeruginosa. Infection 45, 23-31. doi: 10.1007/s15010-0160905-z

Liu, Z., Pan, Y., Li, X., Jie, J., and Zeng, M. (2017d). Chemical composition, antimicrobial and anti-quorum sensing activities of pummelo peel flavonoid extract. Industrial Crops Products 109, 862-868. doi:10.1016/j.indcrop.2017. 09.054

Liu, F., Jin, P., Sun, Z., Du, L., Wang, D., Zhao, T., et al. (2020a). Carvacrol oil inhibits biofilm formation and exopolysaccharide production of Enterobacter cloacae. Food Control 119:107473. doi:10.1016/j.foodcont.2020.1 07473

Liu, F., Sun, Z., Wang, F., Liu, Y., Zhu, Y., Du, L., et al. (2020b). Inhibition of biofilm formation and exopolysaccharide synthesis of Enterococcus faecalis by phenyllactic acid. Food Microbiol. 86:103344. doi:10.1016/j.fm.2019.1 03344

Lories, B., Belpaire, T. E. R., Yssel, A., Ramon, H., and Steenackers, H. P. (2020). Agaric acid reduces Salmonella biofilm formation by inhibiting flagellar motility. Biofilm 2:100022. doi: 10.1016/j.bioflm.2020.100022

Lou, Z., Letsididi, K. S., Yu, F., Pei, Z., Wang, H., and Letsididi, R. (2019). Inhibitive effect of eugenol and its nanoemulsion on quorum sensing-mediated virulence factors and biofilm formation by Pseudomonas aeruginosa. J. Food Prot. 82, 379-389. doi: 10.4315/0362-028x.Jfp-18-196

Martino, D. P., Cafferini, N., Joly, B., and Darfeuille-Michaud, A. (2003). Klebsiella pneumoniae type 3 pili facilitate adherence and biofilm formation on abiotic surfaces. Res. Microbiol. 154, 9-16. doi:10.1016/s0923-2508(02)0 0004-9

Matsumoto-Nakano, M. (2018). Role of Streptococcus mutans surface proteins for biofilm formation. Jpn. Dent. Sci. Rev. 54, 22-29. doi: 10.1016/j.jdsr.2017. 08.002

Melo, T. A., Dos Santos, T. F., Almeida, M. E. D., Junior, L. A. G. F., Andrade, E. F., Rezende, R. P., et al. (2016). Inhibition of Staphylococcus aureus biofilm by Lactobacillus isolated from fine cocoa. BMC Microbiol. 16:250. doi: 10.1186/ s12866-016-0871-8

Merino, L., Trejo, F. M., De Antoni, G., and Golowczyc, M. A. (2019). Lactobacillus strains inhibit biofilm formation of Salmonella sp. isolates from poultry. Food Res. Int. 123, 258-265. doi: 10.1016/j.foodres.2019.04.067

Miryala, S., Makala, H., Yadavali, S. P., Venkatasubramanian, U., Subbaiah, N., and Srinandan, C. S. (2020). Disperse red 15 (DR15) impedes biofilm formation of uropathogenic Escherichia coli. Microb. Pathog. 138:103772. doi: 10.1016/j. micpath.2019.103772

Mohammed, Y. H. E., Manukumar, H. M., Rakesh, K. P., Karthik, C. S., Mallu, P., and Qin, H. L. (2018). Vision for medicine: staphylococcus aureus biofilm war and unlocking key's for anti-biofilm drug development. Microb. Pathog. 123, 339-347. doi: 10.1016/j.micpath.2018.07.002
Mugita, N., Nambu, T., Takahashi, K., Wang, P. L., and Komasa, Y. (2017). Proteases, actinidin, papain and trypsin reduce oral biofilm on the tongue in elderly subjects and in vitro. Arch. Oral Biol. 82, 233-240. doi: 10.1016/j. archoralbio.2017.04.035

Nadaf, N. H., Parulekar, R. S., Patil, R. S., Gade, T. K., Momin, A. A., Waghmare, S. R., et al. (2018). Biofilm inhibition mechanism from extract of Hymenocallis littoralis leaves. J. Ethnopharmacol. 222, 121-132. doi:10.1016/j.jep.2018. 04.031

Nickzad, A., Lépine, F., and Déziel, E. (2015). Quorum sensing controls swarming motility of burkholderia glumae through regulation of rhamnolipids. PLoS One 10:e0128509. doi: 10.1371/journal.pone.0128509

Ning, Y., Yan, A., Yang, K., Wang, Z., Li, X., and Jia, Y. (2017). Antibacterial activity of phenyllactic acid against Listeria monocytogenes and Escherichia coli by dual mechanisms. Food Chem. 228, 533-540. doi:10.1016/j.foodchem.2017. 01.112

Oknin, H., Steinberg, D., and Shemesh, M. (2015). Magnesium ions mitigate biofilm formation of Bacillus species via downregulation of matrix genes expression. Front. Microbiol. 6:907. doi: 10.3389/fmicb.2015. 00907

Okshevsky, M., and Meyer, R. L. (2015). The role of extracellular DNA in the establishment, maintenance and perpetuation of bacterial biofilms. Crit. Rev. Microbiol. 41, 341-352. doi: 10.3109/1040841x.2013.841639

Okshevsky, M., Regina, V. R., and Meyer, R. L. (2015). Extracellular DNA as a target for biofilm control. Curr. Opin. Biotechnol. 33, 73-80. doi: 10.1016/j.copbio. 2014.12.002

Opoku-Temeng, C., and Sintim, H. O. (2017). Targeting c-di-GMP signaling, biofilm formation, and bacterial motility with small molecules. Methods Mol. Biol. 1657, 419-430. doi: 10.1007/978-1-4939-7240-1_31

Otani, S., Hiramatsu, K., Hashinaga, K., Komiya, K., Umeki, K., Kishi, K., et al. (2018). Sub-minimum inhibitory concentrations of ceftazidime inhibit Pseudomonas aeruginosa biofilm formation. J. Infect. Chemother. 24, 428-433. doi: 10.1016/j.jiac.2018.01.007

Paharik, A. E., and Horswill, A. R. (2016). The staphylococcal biofilm: adhesins, regulation, and host response. Microbiol. Spectr. 4:10.1128/microbiolsec.VMBF-0022-2015. doi: 10.1128/microbiolspec.VMBF0022-2015

Pakkulnan, R., Anutrakunchai, C., Kanthawong, S., Taweechaisupapong, S., Chareonsudjai, P., and Chareonsudjai, S. (2019). Extracellular DNA facilitates bacterial adhesion during Burkholderia pseudomallei biofilm formation. PLoS One 14:e0213288. doi: 10.1371/journal.pone.0213288

Parai, D., Banerjee, M., Dey, P., and Mukherjee, S. K. (2020). Reserpine attenuates biofilm formation and virulence of Staphylococcus aureus. Microb. Pathog. 138:103790. doi: 10.1016/j.micpath.2019.103790

Parastan, R., Kargar, M., Solhjoo, K., and Kafilzadeh, F. (2020). Staphylococcus aureus biofilms: structures, antibiotic resistance, inhibition, and vaccines. Gene Reports. 20:100739. doi: 10.1016/j.genrep.2020.100739

Park, B. S., Kim, J. G., Kim, M. R., Lee, S. E., Takeoka, G. R., Oh, K. B., et al. (2005). Curcuma longa L. constituents inhibit sortase A and Staphylococcus aureus cell adhesion to fibronectin. J. Agric. Food Chem. 53, 9005-9009. doi: 10.1021/jf051765z

Patriquin, G. M., Banin, E., Gilmour, C., Tuchman, R., Greenberg, E. P., and Poole, K. (2008). Influence of quorum sensing and iron on twitching motility and biofilm formation in Pseudomonas aeruginosa. J. Bacteriol. 190, 662-671. doi: 10.1128/jb.01473-07

Peng, L., Chang, L., Liu, X., Lin, J., Liu, H., Han, B., et al. (2017). Antibacterial property of a polyethylene glycol-grafted dental material. ACS Appl. Mater. Interfaces 9, 17688-17692. doi: 10.1021/acsami.7b05284

Peterson, M. M., Mack, J. L., Hall, P. R., Alsup, A. A., Alexander, S. M., Sully, E. K., et al. (2008). Apolipoprotein B Is an innate barrier against invasive Staphylococcus aureus infection. Cell. Host Microbe 4, 555-566. doi: 10.1016/ j.chom.2008.10.001

Pundir, C. S., Lata, S., and Narwal, V. (2018). Biosensors for determination of D and L- amino acids: a review. Biosens Bioelectron. 117, 373-384. doi: 10.1016/j. bios.2018.06.033

Rabin, N., Zheng, Y., Opoku-Temeng, C., Du, Y., Bonsu, E., and Sintim, H. O. (2015). Biofilm formation mechanisms and targets for developing antibiofilm agents. Future Med. Chem. 7, 493-512. doi: 10.4155/fmc.15.6 
Rajivgandhi, G. N., Ramachandran, G., Maruthupandy, M., Manoharan, N., Alharbi, N. S., Kadaikunnan, S., et al. (2020). Anti-oxidant, anti-bacterial and anti-biofilm activity of biosynthesized silver nanoparticles using Gracilaria corticata against biofilm producing K. pneumoniae. Colloids Surfaces A 600:124830. doi: 10.1016/j.colsurfa.2020.124830

Ramón-Peréz, M. L., Diaz-Cedillo, F., Ibarra, J. A., Torales-Cardeñ;a, A., Rodríguez-Martínez, S., Jan-Roblero, J., et al. (2014). D-Amino acids inhibit biofilm formation in Staphylococcus epidermidis strains from ocular infections. J. Med. Microbiol. 63(Pt 10), 1369-1376. doi:10.1099/jmm.0.075 796-0

Reen, F. J., Gutiérrez-Barranquero, J. A., Parages, M. L., and Gara, F. O. (2018). Coumarin: a novel player in microbial quorum sensing and biofilm formation inhibition. Appl. Microbiol. Biotechnol. 102, 2063-2073. doi: 10.1007/s00253018-8787-x

Rumbaugh, K. P., and Sauer, K. (2020). Biofilm dispersion. Nat. Rev. Microbiol. 18, 571-586. doi: 10.1038/s41579-020-0385-0

Schlafer, S., Meyer, R. L., Dige, I., and Regina, V. R. (2017). Extracellular DNA contributes to dental biofilm stability. Caries Res. 51, 436-442. doi: 10.1159/ 000477447

Shaaban, M., Elgaml, A., and Habib, E. E. (2019). Biotechnological applications of quorum sensing inhibition as novel therapeutic strategies for multidrug resistant pathogens. Microb. Pathog. 127, 138-143. doi: 10.1016/j.micpath.2018. 11.043

Sharma, G., Sharma, S., Sharma, P., Chandola, D., Dang, S., Gupta, S., et al. (2016). Escherichia coli biofilm: development and therapeutic strategies. J. Appl. Microbiol. 121, 309-319. doi: 10.1111/jam.13078

She, P., Chen, L., Liu, H., Zou, Y., Luo, Z., Koronfel, A., et al. (2015). The effects of D-Tyrosine combined with amikacin on the biofilms of Pseudomonas aeruginosa. Microb. Pathog. 86, 38-44. doi: 10.1016/j.micpath.2015.07.009

Sheng, G. P., and Yu, H. Q. (2006). Relationship between the extracellular polymeric substances and surface characteristics of Rhodopseudomonas acidophila. Appl. Microbiol. Biotechnol. 72, 126-131. doi: 10.1007/s00253-0050225-1

Shokri, D., Khorasgani, M. R., Mohkam, M., Fatemi, S. M., Ghasemi, Y., and Taheri-Kafrani, A. (2018). The inhibition effect of lactobacilli against growth and biofilm formation of Pseudomonas aeruginosa. Probiotics Antimicrob. Proteins 10, 34-42. doi: 10.1007/s12602-017-9267-9

Shukla, S. K., and Rao, T. S. (2017). Staphylococcus aureus biofilm removal by targeting biofilm-associated extracellular proteins. Indian J. Med. Res. 146, S1-S8. doi: 10.4103/ijmr.IJMR_410_15

Silva, S. S. E., Carvalho, J. W. P., Aires, C. P., and Nitschke, M. (2017). Disruption of Staphylococcus aureus biofilms using rhamnolipid biosurfactants. J. Dairy Sci. 100, 7864-7873. doi: 10.3168/jds.2017-13012

Solano, C., Echeverz, M., and Lasa, I. (2014). Biofilm dispersion and quorum sensing. Curr. Opin. Microbiol. 18, 96-104. doi:10.1016/j.mib.2014. 02.008

Spangler, C., Kaever, V., and Seifert, R. (2011). Interaction of the diguanylate cyclase YdeH of Escherichia coli with 2,(3')-substituted purine and pyrimidine nucleotides. J. Pharmacol. Exp. Ther. 336, 234-241. doi: 10.1124/jpet.110. 170993

Steiner, S., Lori, C., Boehm, A., and Jenal, U. (2013). Allosteric activation of exopolysaccharide synthesis through cyclic di-GMP-stimulated protein-protein interaction. Embo J. 32, 354-368. doi: 10.1038/emboj.2012.315

Stephens, K., and Bentley, W. E. (2020). Synthetic biology for manipulating quorum sensing in microbial consortia. Trends Microbiol. 28, 633-643. doi: 10.1016/j.tim.2020.03.009

Stobie, N., Duffy, B., Hinder, S. J., McHale, P., and McCormack, D. E. (2009). Silver doped perfluoropolyether-urethane coatings: antibacterial activity and surface analysis. Colloids Surf B Biointerfaces 72, 62-67. doi:10.1016/j.colsurfb.2009. 03.014

Sun, F., Yuan, Q., Wang, Y., Cheng, L., Li, X., Feng, W., et al. (2020). Sub-minimum inhibitory concentration ceftazidime inhibits Escherichia coli biofilm formation by influencing the levels of the ibpA gene and extracellular indole. J. Chemother. 32, 7-14. doi: 10.1080/1120009x.2019.1678913

Swartjes, J. T. M., Das, T., Sharifi, S., Subbiahdoss, G., Sharma, P. K., Krom, B. P., et al. (2013). A functional DNase I coating to prevent adhesion of bacteria and the formation of biofilm. Adv. Funct. Mater. 23, 2843-2849. doi: 10.1002/adfm. 201202927
Tang, D., Gao, Q., Zhao, Y., Li, Y., Chen, P., Zhou, J., et al. (2018). Mg2+ reduces biofilm quantity in Acidithiobacillus ferrooxidans through inhibiting Type IV pili formation. FEMS Microbiol. Lett. 365:fnx266. doi: 10.1093/femsle/f nx266

Trentin, D. S., Silva, D. B., Amaral, M. W., Zimmer, K. R., Silva, M. V., Lopes, N. P., et al. (2013). Tannins possessing bacteriostatic effect impair Pseudomonas aeruginosa adhesion and biofilm formation. PLoS One 8:e66257. doi: 10.1371/ journal.pone. 0066257

Tseng, B. S., Reichhardt, C., Merrihew, G. E., Araujo-Hernandez, S. A., Harrison, J. J., MacCoss, M. J., et al. (2018). A biofilm matrix-associated protease inhibitor protects Pseudomonas aeruginosa from proteolytic attack. mBio 9, e543-e518. doi: $10.1128 / \mathrm{mBio} .00543-18$

Venkatesan, N., Perumal, G., and Doble, M. (2015). Bacterial resistance in biofilm-associated bacteria. Future Microbiol. 10, 1743-1750. doi: 10.2217/fmb. 15.69

Veras, H. N., Rodrigues, F. F. G., Botelho, M. A., Menezes, I. R. A., Coutinho, H. D. M., and Costa, J. G. D. (2014). Antimicrobial effect of Lippia sidoides and thymol on Enterococcus faecalis biofilm of the bacterium isolated from root canals. Sci. World J. 2014:471580. doi: 10.1155/2014/471580

Vuotto, C., and Donelli, G. (2019). Novel treatment strategies for biofilmbased infections. Drugs 79, 1635-1655. doi: 10.1007/s40265-019-0 $1184-\mathrm{z}$

Wang, H., Chu, W., Ye, C., Gaeta, B., Tao, H., Wang, M., et al. (2019). Chlorogenic acid attenuates virulence factors and pathogenicity of Pseudomonas aeruginosa by regulating quorum sensing. Appl. Microbiol. Biotechnol. 103, 903-915. doi: $10.1007 / \mathrm{s} 00253-018-9482-7$

Wang, L., Zhao, X., Zhu, C., Xia, X., Qin, W., Li, M., et al. (2017). Thymol kills bacteria, reduces biofilm formation, and protects mice against a fatal infection of Actinobacillus pleuropneumoniae strain L20. Vet. Microbiol. 203, 202-210. doi: 10.1016/j.vetmic.2017.02.021

Wang, W., Yan, Y., Zhao, Y., Shi, Q., and Wang, Y. (2020). Characterization of stratified EPS and their role in the initial adhesion of anammox consortia. Water Res. 169:115223. doi: 10.1016/j.watres.2019.115223

Wu, C., Lin, C., Wu, C., Peng, W., Lee, M. J., and Tsai, Y. C. (2015). Inhibitory effect of Lactobacillus salivarius on Streptococcus mutans biofilm formation. Mol. Oral Microbiol. 30, 16-26. doi: 10.1111/omi.12063

Wu, S., Liu, J., Liu, C., Yang, A., and Qiao, J. (2020). Quorum sensing for population-level control of bacteria and potential therapeutic applications. Cell Mol. Life Sci. 77, 1319-1343. doi: 10.1007/s00018-019-03326-8

Xia, S., Zhou, L., Zhang, Z., and Li, J. (2012). Influence and mechanism of N(3-oxooxtanoyl)-L-homoserine lactone (C8-oxo-HSL) on biofilm behaviors at early stage. J. Environ. Sci. (China) 24, 2035-2040. doi: 10.1016/s1001-0742(11) 61060-7

Xing, S., Sun, X., Taylor, A. A., Walker, S. L., Wang, Y., and Wang, S. (2015). D-amino acids inhibit initial bacterial adhesion: thermodynamic evidence. Biotechnol. Bioeng. 112, 696-704. doi: 10.1002/bit.25479

$\mathrm{Xu}, \mathrm{H}$., and Liu, Y. (2011). d-Amino acid mitigated membrane biofouling and promoted biofilm detachment. J. Membrane Sci. 376, 266-274. doi: 10.1016/ j.memsci.2011.04.030

Yan, J., and Bassler, B. L. (2019). Surviving as a community: antibiotic tolerance and persistence in bacterial biofilms. Cell Host Microbe 26, 15-21. doi: 10.1016/ j.chom.2019.06.002

Yan, X., Gu, S., Cui, X., Shi, Y., Wen, S., Chen, H., et al. (2019). Antimicrobial, anti-adhesive and anti-biofilm potential of biosurfactants isolated from Pediococcus acidilactici and Lactobacillus plantarum against Staphylococcus aureus CMCC26003. Microb. Pathog. 127, 12-20. doi: 10.1016/j.micpath.2018. 11.039

Yu, C., Li, X., Zhang, N., Wen, D., Liu, C., and Li, Q. (2016). Inhibition of biofilm formation by D-tyrosine: effect of bacterial type and D-tyrosine concentration. Water Res. 92, 173-179. doi: 10.1016/j.watres.2016.01.037

Yu, R., Hou, C., Liu, A., Peng, T., Xia, M., Wu, X., et al. (2018). Extracellular DNA enhances the adsorption of Sulfobacillus thermosulfidooxidans strain ST on chalcopyrite surface. Hydrometallurgy 176, 97-103. doi: 10.1016/j.hydromet. 2018.01.018

Yu, S., Wei, Q., Zhao, T., Guo, Y., and Ma, L. Z. (2016). A survival strategy for Pseudomonas aeruginosa that uses exopolysaccharides to sequester and store iron to stimulate Psl-Dependent biofilm formation. Appl. Environ. Microbiol. 82, 6403-6413. doi: 10.1128/aem.01307-16 
Zea, L., McLean, R. J. C., Rook, T. A., Angle, G., Carter, D. L., Delegard, A., et al. (2020). Potential biofilm control strategies for extended spaceflight missions. Biofilm 2:100026. doi: 10.1016/j.bioflm.2020.100026

Zhang, Y., Fu, Y., Yu, J., Ai, Q., Li, J., Peng, N., et al. (2015). Synergy of ambroxol with vancomycin in elimination of catheter-related Staphylococcus epidermidis biofilm in vitro and in vivo. J. Infect. Chemother. 21, 808-815. doi: 10.1016/j.jiac. 2015.08.017

Zhang, Y., Sass, A., Acker, H. V., Wille, J., Verhasselt, B., Nieuwerburgh, F. V., et al. (2018). Coumarin reduces virulence and biofilm formation in Pseudomonas aeruginosa by affecting quorum sensing, Type III secretion and C-di-GMP levels. Front. Microbiol. 9:1952. doi:10.3389/fmicb.2018. 01952

Zou, M., and Liu, D. (2020). Effects of carbon sources and temperature on the formation and structural characteristics of food-related Staphylococcus epidermidis biofilms. Food Sci. Hum. Wellness 9, 370-376. doi: 10.1016/j.fshw. 2020.05.007

Conflict of Interest: The authors declare that the research was conducted in the absence of any commercial or financial relationships that could be construed as a potential conflict of interest.

Copyright $\odot 2021 \mathrm{Fu}$, Zhang, Lin, Zhang, Shu, Lin, Li, Xu, Tang, Peng, Zhao, Chen and $F u$. This is an open-access article distributed under the terms of the Creative Commons Attribution License (CC BY). The use, distribution or reproduction in other forums is permitted, provided the original author(s) and the copyright owner(s) are credited and that the original publication in this journal is cited, in accordance with accepted academic practice. No use, distribution or reproduction is permitted which does not comply with these terms. 